\title{
ВНУТРЕННИЙ МАРКЕТИНГ КАК ВАЖНЕЙШЕЕ НАПРАВЛЕНИЕ УПРАВЛЕНИЯ ЧЕЛОВЕЧЕСКИМ КАПИТАЛОМ В ЦИФРОВОЙ ЭКОСИСТЕМЕ СБЕРБАНКА РОССИИ
}

\author{
(c) 2018 Ермолаев Константин Николаевич \\ доктор экономических наук, профессор \\ Заведующий кафедрой «Институциональная экономика и экономическая история» \\ Самарский государственный экономический университет \\ 443090, г. Самара, ул. Советской Армии, д. 141 \\ E-mail: ermolaevkn@yandex.ru \\ (c) 2018 Коржова Галина Анатольевна \\ кандидат экономических наук, доцент \\ Самарский государственный экономический университет \\ 443090, г. Самара, ул. Советской Армии, д. 141 \\ E-mail: korzhova-galina@yandex.ru
}

Внутренний маркетинг как важнейшее направление управления человеческим капиталом является неотъемлемым элементом цифровой экосистемы, создаваемой основе инфраструктуры Сбербанка и способной покрыть следующие отраслевые группы: потребительские товары, недвижимость, образование, здравоохранение, путешествия и отдых, телекоммуникации, госуслуги, разработку софта и приложений, бизнес-услуги, строительство, производство, финансовые сервисы.

Ключевые слова: цифровая экосистема, внутренний маркетинг, человеческий капитал, цифровизация, управление персоналом.

Актуальность создания системы внутреннего маркетинга как элемента управления человеческим капиталом Сбербанка РФ обусловлена возникновением следующих глобальных проблем.

Во-первых, это изменение потребительских предпочтений клиентов. С каждым годом всё большую часть клиентов составляют молодые люди поколений $\mathrm{Y}$ и Z - родившихся после 1982 и 2000 года рождения. Главная черта этих поколений - это переход на цифровую среду во всех сферах жизнедеятельности, 96\% их представителей считают смартфон самым важным персональным устройством в своей жизни. Эксперты McKinsey в обзоре «Цифровая Россия» пишут следующее: «Российские банки находятся сегодня на низком старте и обладают прекрасной возможностью быстро перевести клиентов на современные каналы дистанционного обслуживания». Относительно проникновения дистанционного банковского обслуживания, Россия отстает от более развитых рынков на 4-6 лет, а дистанционными банковскими услугами пользуются только 30\% клиентов банков, в то время как в США и Северной Европе - 60\%, считает McKinsey [1]. Как говорилось в популярной сейчас рекламной кампании ҮОТА: «Всё вокруг ста- новится приложением», подразумевая именно digital-приложения.

Во-вторых, это развитие новых банковских технологий. Новые технологии, постоянно развиваясь, трансформируют привычные способы предоставления банковских услуг. Теперь лидерство в области технологических разработок (облачные технологии, интернет вещей, искусственный интеллект, блокчейн, кибербезопасность, виртуальная и дополненная реальность, геймификация, робототехника, биометрическая идентификация) определяет лидерство на рынке [2].

B-третьих, снижение маржинальности мирового банковского сектора и усиление регуляторных требований. Показатель рентабельности глобальной банковской системы находится на стабильном, невысоком уровне последние 5 лет - в среднем 9\%. Ожидается переход на новый международный формат отчетности, который потребует формирование банковских резервов не на основе понесенных убытков, а на основе прогнозируемых затрат. Появление директивы Европейского союза об оказании платежных услуг будет оказывать влияние на финансовые транзакции. Ожидается, что допол- 
нительные меры регулирования будут приводить к дополнительным затратам и росту конкуренции [2].

В-четвертых, возникновением новой экономики экосистем. Новое явление в экономике - цифровые экосистемы, которые сформировались на основе развития цифровых технологий и породили собой поведенческое изменение потребительских предпочтений. Экосистема в данном контексте - это сеть организаций, создающихся вокруг технологической платформы и пользующихся её услугами по формированию лучших предложений клиентам и доступу к ним для удовлетворения конечных потребностей клиентов - физических и юридических лиц. Эта технологическая платформа позволяет в режиме реального времени за счет открытых API интерфейсов, машинного обучения, облачных технологий и анализа больших данных с определенно заданным уровнем безопасности формировать лучшее предложение для клиента как из собственных товаров и услуг, так и за счет подключения внешних провайдеров продуктов или сервисов. Главным в экосистеме является владелец непосредственно технологической платформы, который способен не просто собрать вокруг себя производителей товаров и услуг, но и эффективно манипулировать ими, формируя лучшее предложения для клиентов на основе анализа потребительского поведения. По оценкам экспертов, к 2025 году цифровые экосистемы могут охватить до 30\% выручки в регионах присутствия. Это будет достигнуто за счет оптимизации цепочки посредников между провайдерами товаров и услуг и потребителями [2].

Современная стратегия развития Сбербанка исходит из необходимости создания «национальной экосистемы» в сфере интернет коммерции по примеру крупнейших мировых компаний, чтобы оказывать услуги как конечным потребителям, так и бизнесу в самых различных областях - от образования и здравоохранения до строительства и потребительских товаров.

Под экосистемой подразумевается построение сети организаций, создающихся вокруг единой технологической платформы и пользующихся ее услугами для формирования предложений клиентам и доступа к ним. Примеры крупнейших таких экосистем - это американские Google, Amazon, Facebook; китайские Telectnt и Alibaba. По прогнозу Сбербанка к 2025 годы на такие экосистемы придется около 30\% глобальной выручки организаций и более $40 \%$ их глобальной прибыли. К 2025 году объем экосистемы Сбербанка может составить 65 трлн. Рублей, для сравнения ВВП РФ за 2015 год составил 80,4 трлн.руб. Построение экосистемы должно произойти на основе инфраструктуры Сбербанка и покрыть, как считают в банке, следующие отраслевые группы: потребительские товары, недвижимость, образование, здравоохранение, путешествия и отдых, телекоммуникации, госуслуги, разработку софта и приложений, бизнес-услуги, строительство, производство, финансовые сервисы.

Неотъемлемой экосистемы Сбербанка РФ должна стать организация внутреннего маркетинга. Определение процессов внутреннего маркетинга было впервые описано известной фирмой McKinsey в одноимённой книге в результате проведения масштабных исследований с целью выяснить - каким образом отношение к сотрудникам определяет успех компании. Исследования убедительно показывают, что успешные компании не просто совершенствуют процедуры и нормы управления человеческим капиталом. В современном мире выигрывают те организации, которые сами, как товар, являются наиболее привлекательными на рынке труда. Это те компании, которые делают всё, чтобы привлечь, помочь развитию и удержать наиболее талантливых сотрудников на всех уровнях управленческих организаций [3].

В литературе присутствуют различные трактовки внутреннего маркетинга: как планомерных действий по использованию маркетинговых методов внутри организации, направленных на преодоление сопротивления изменениям, мотивацию и межфункциональную интеграцию сотрудников с целью эффективной реализации стратегии удовлетворения клиентов через философию создания мотивированного и клиентоориентированного персонала [4] (Рафик М. и Ахмед П.К.); как процесса создания благоприятных условий работы сотрудников и управление взаимоотношениями между внутренними поставщиками и внутренними потребителями с целью удовлетворения последних [5]; как философия отношения к работнику как к клиенту и стратегия создания работы-продукта в соответствии с потребностями сотрудника-клиента [5] (Берри Л. и Парасураман А.); как любая форма маркетинга внутри организации, которая акцентирует внимание персонала на внутренних 
действиях, которые должны быть изменены для улучшения положения организации на рынке [5] (Баллантайн Д.); как управление обменными процессами между участниками внутреннего рынка организации, суть которых связана с ориентацией на клиента [5] (Страусс Дж. и Шульц П.); как программа по уменьшению изоляции отделов организации межфункциональных разногласий, а также по преодолению сопротивления сотрудников нововведениям [5] (Мартин, Дарлинг и Тейлор).

По нашему мнению, определение Страусса Дж. и Шульца П. более остальных раскрывает истинный смысл внутреннего маркетинга - ориентация на внешнего клиента за счет успешной оптимизации внутренних процессов.

История развития концепции внутреннего маркетинга берет начало в 1970-х. Тогда актив- но развивался маркетинг услуг, и если в начале семидесятых это понятие только зарождалось в ответ на явление, прозванное «революцией в секторе услуг», то уже в середине начали появляться первые модели маркетинга услуг. Сначала это была модель Д. Ратмела (1974), которая показывала одновременность процесса производства и потребления услуги, что говорило о появлении новой функциональной задачи маркетинга в сфере услуг. Появляется потребность изучать, внедрять, рекламировать, оценивать и продавать процесс взаимодействия между производителями услуги и её потребителями. На рисунке 1.1 эта задача обозначена дополнительной стрелкой.

Следующая модель была представлена в 1976 году профессорами П. Эйглие и Е. Лангеард (рисунок 1.2). Если в модели Д. Ратмела отража-

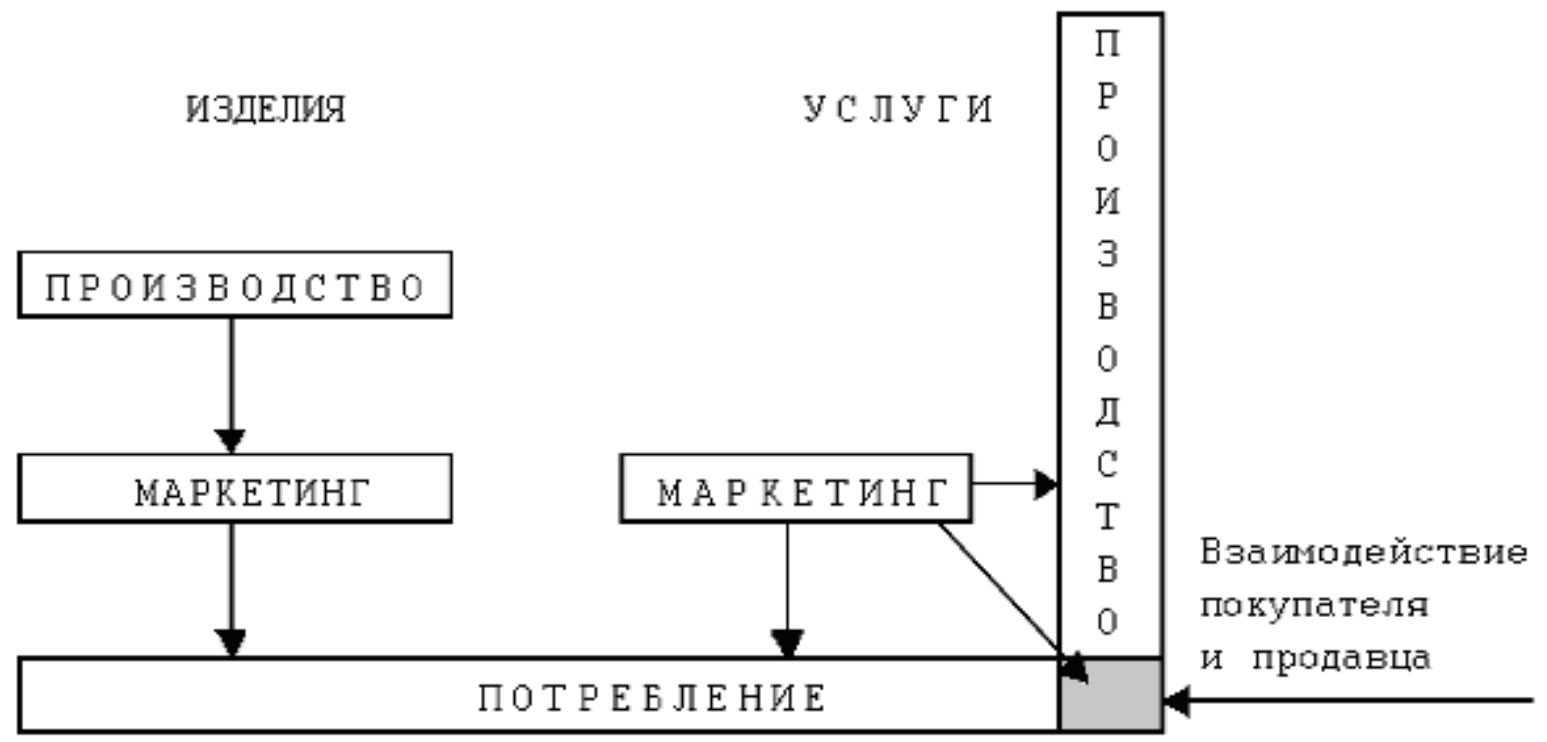

Рuc. 1.1. Модель маркетинга услуг Д. Ратмела

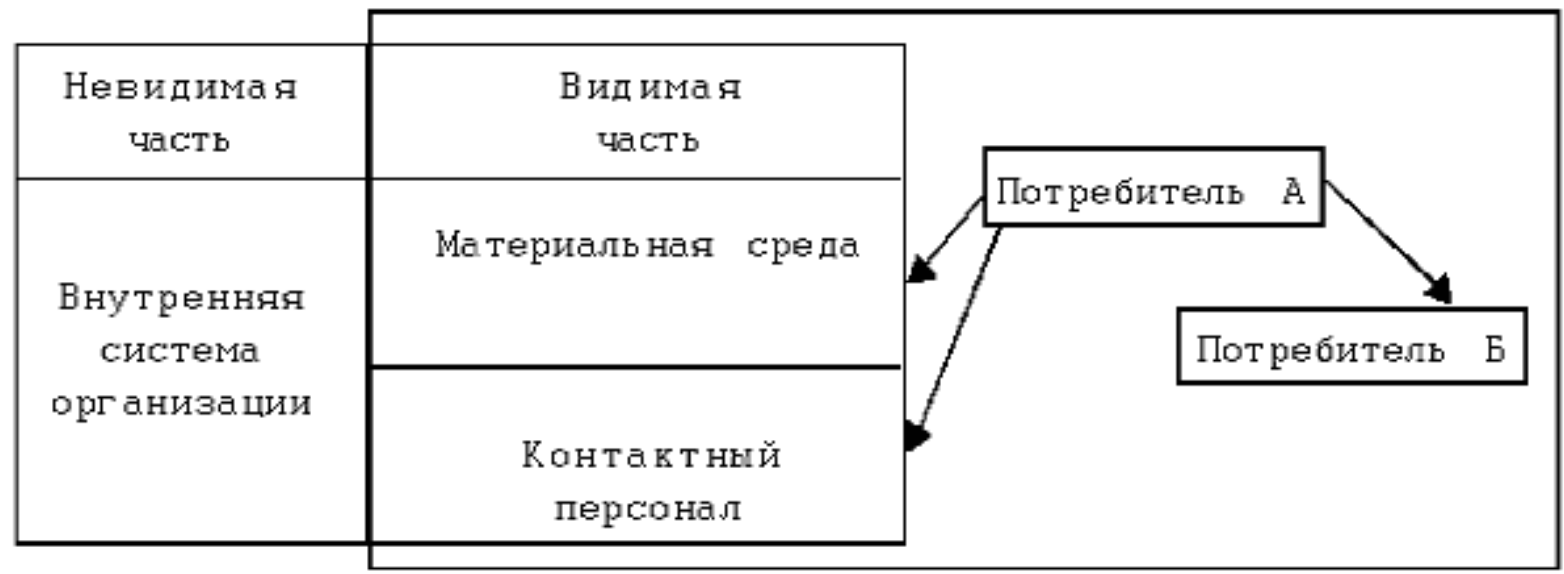

Puc. 1.2. Модель маркетинга услуг П. Эйглие и Е. Лангеарда [6] 
лась лишь необходимость оказания внимания взаимодействию продавца и покупателя как новая функциональная задача маркетинга, то в этой модели подробно отражается весь процесс оказания услуги. Согласно модели, помимо основных стратегий - каналов распределения, цен и товара, менеджер по маркетингу должен был продумать три дополнительных стратегии: видимая часть компании, которую сможет оценить потребитель - дизайн помещения для обслуживания клиента; нормы поведения сотрудников во время процесса оказания услуги - обучение и мотивация персонала; и сегментация потребителей.

Говоря о развитии концепции внутреннего маркетинга, важно упомянуть модель производства, так называемый «marketing mix» или 4P (product, price, place, promotion), разработанную в 1960-х Джеромом Маккарти - рис. 1.3. Филип Котлер популяризировал этот подход и помог его распространить. В рамках маркетинга услуг, в 1981 году, другие исследователи, М. Битнер и Б. Бумс, расширили эту модель ещё тремя «Р» (process, physical evidence, people) - рисунок 1.4. Как можно заметить, согласно этой модели, одним из этих трёх факторов формирования услуги является именно персонал [7].

В 1981 г. Л. Берри (профессор бизнес-школы, директор множества компаний) опубликовал статью «Работник как клиент», в которой рассматривал банковский персонал, обслуживающий потребителей, как внутренних клиентов.
Позднее, около 1990, Кристиан Гринрос, представитель Северной школы маркетинга услуг «Nordic school», представил свою модель, которая в значительной степени основана на моделях Д. Ратмела и П. Эйглие / Е. Лангеарда. Именно Северная школа маркетинга услуг разработала концепцию внутреннего маркетинга, концепцию качества услуги и концепцию интерактивного маркетинга. Кристиан Гринрос называет интерактивным маркетингом то, что Д. Ратмел называл «дополнительной функцией маркетинга», то есть нацеливание на процесс взаимодействия продавца и клиента. Основной задачей интерактивного маркетинга, по мнению К. Гринроса, является создание и продвижение высоких стандартов обслуживания. Поведение персонала в этом случае становится одним из основных факторов, поэтому К. Гринрос ввел ещё две концепции: внутренний маркетинг и функционально-инструментальную модель качества обслуживания.

Позднее, около 2000 г., Филип Котлер разработал треугольную концептуальную модель маркетинга услуг (рис. 1.5). В её основе лежат три взаимосвязанные единицы: руководство фирмы, контактный персонал и потребители. Их взаимосвязь образует три звена: фирма-потребитель, фирма-персонал, персонал-потребитель. Для эффективного управления маркетингом в сфере услуг необходимо развивать три стратегии, направленные на эти три звена. Это стратегия традиционного маркетинга, опирающаяся

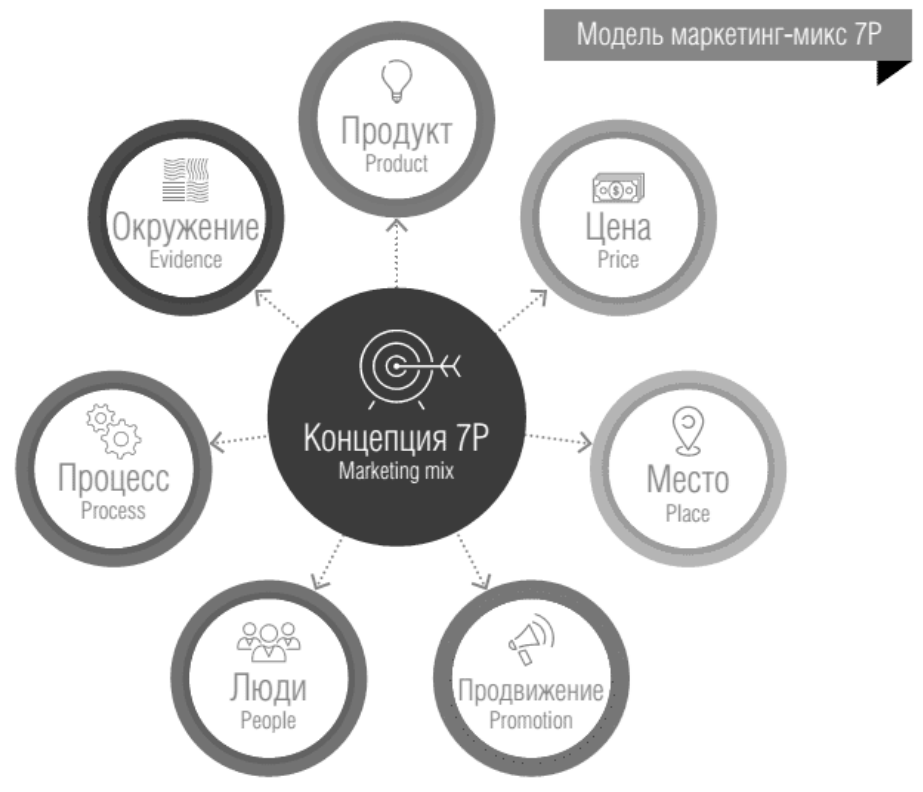

Рuc. 1.4. 7Р модель Б. Бумса и М. Битнера

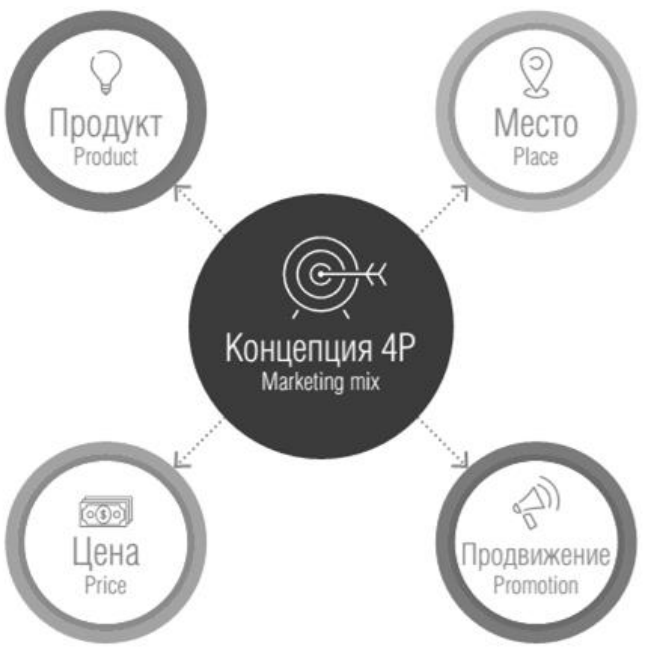

Puc. 1.3. 4Р модель Д. Маккарти 


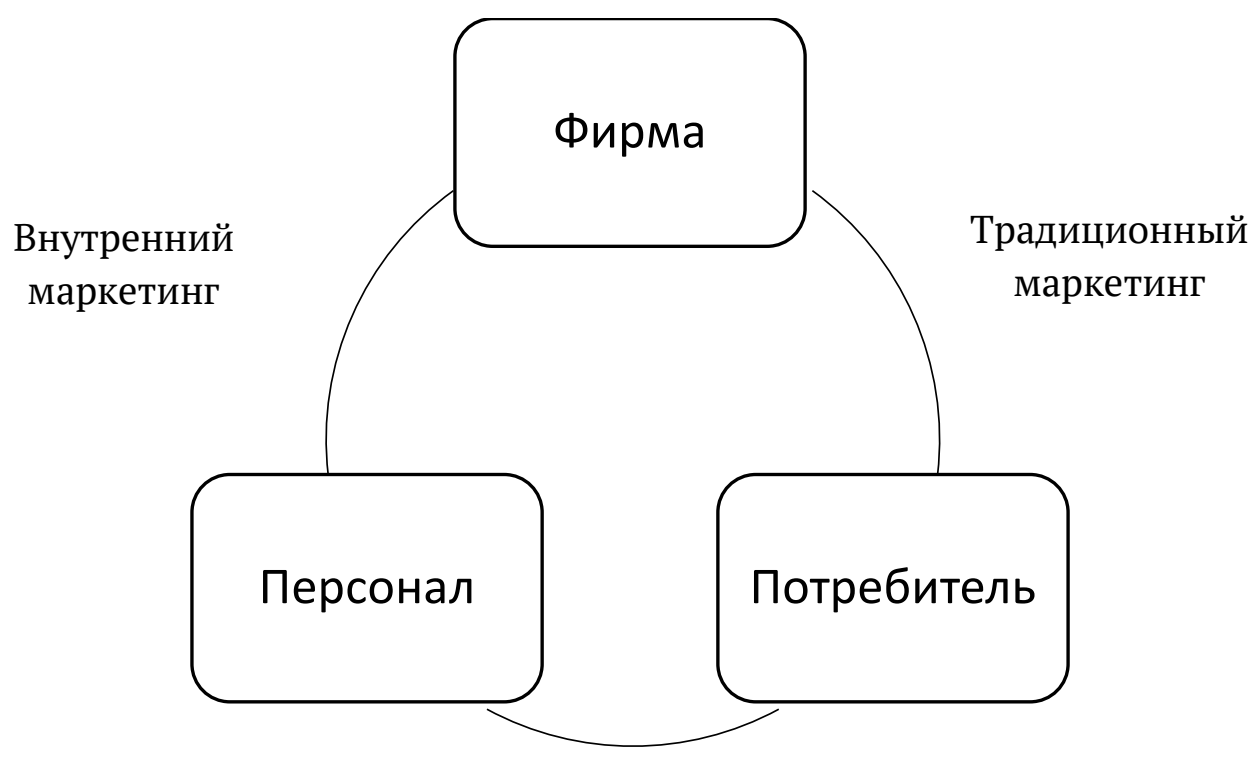

Интерактивный маркетинг

Рuc. 1.5. Графическая интерпретация треугольной модели маркетинга услуг Ф. Котлера [10]

на ценообразование, коммуникации, распространение и направленная на звено «фирма-потребитель». Также это стратегия интерактивного маркетинга, отвечающая за контроль качества оказания услуги и направленная на звено «персонал-потребитель» [8]. И, наконец, стратегия внутреннего маркетинга, направленная на звено «фирма-персонал» и связанная с мотивацией персонала на качественное обслуживание клиентов. То есть Филип Котлер определял внутренний маркетинг как один из важнейших компонентов успешного ведения бизнеса [9].

Поскольку внутренний маркетинг персонала сейчас является одной из ключевых тенденций ведения бизнеса, в Сбербанке России начали появляться маркетинговые стратегии не только для привлечения потребителей, но и для удержания существующих и привлечения новых внутренних клиентов. Такие маркетинговые стратегии со временем перетекли в целую систему предоставления услуг внутренним клиентам, а после её автоматизации, модификации и оптимизации - в целую программу на базе технических платформ.

Программа внутреннего маркетинга услуг ПАО Сбербанк, которая была внедрена в систему в 2016 году, включает в себя внедрение:
- специального программного обеспечения на любых цифровых носителях для внутренних клиентов по созданию заявок на получение услуги и написания жалоб (портал ДРУГ);

- программного обеспечения для сотрудников обеспечивающих подразделений по внесению информации об обработке заявок;

- онлайн отчетности для руководящих сотрудников;

- общих принципов построения офлайн отчетности;

- еженедельные, ежемесячные и ежеквартальные встречи руководства для принятия решений;

- системы дисциплинарных взысканий;

- договоры об уровне сервиса с каждым обеспечивающим подразделением;

- специальных подразделений - Офисов ДРУГ (Дирекций распределенных услуг) для контроля за отработкой заявок, внедрения новых услуг и улучшения имеющихся.

Основным структурным подразделением по работе с внутренними клиентами, то есть, персоналом Банка, являются Офисы дирекции распределенных услуг. Данное подразделение располагается территориально в каждом регионе Российской Федерации. К примеру, в зону ответ- 
ственности Офиса ДРУГ Поволжского банка ПАО Сбербанк входят услуги, оказываемые в таких городах, как: Астрахань, Самара, Тольятти, Пенза, Саратов, Волгоград, Оренбург и Ульяновск. Помимо этого, существует центральный офис в Москве, курирующий работу всех «Друзей» и дополнительный Сервисный центр распределенных услуг центрального подчинения, находящийся в Нижнем Новгороде.

Данный сервисный центр оказывает онлайн и телефонную поддержку всем сотрудникам ПАО Сбербанк по работе с порталом по оказанию внутренних услуг, созданию заявок, выборе необходимого шаблона и других возникающих проблем в их работе. Кроме того, в Сервисном центре создается основная документация, регламентирующая работу Офисов ДРУГ, общепринятая форма офлайн отчетности для центрального и территориального Офисов, а также разработка и поддержка онлайн отчетности по всем обрабатываемым заявкам внутренних клиентов.

Из проведенного исследования можно сделать вывод, что, несмотря на отсутствие общепринятого определения внутреннего маркетинга, многие крупные компании инвестируют в его реализацию, уделяя внимание не только настоящим внутренним клиентам, а также прошлым и будущим. Процесс работы с лояльностью сотрудников долгосрочен и включает в себя последовательные шаги по формированию лояльного персонала, ориентированного на достижение не только личных целей, но и целей организации.

Таким образом, недостаточно просто организовать внутренний маркетинг в компании на основании выявленных факторов лояльности. Необходимо проводить своевременную, систематическую, качественную и количественную оценку удовлетворенности внутренних клиентов, систематически проводить личный контроль руководителями за внутренними процессами, своевременно организовывать встречи руководства для обсуждения текущих показателей и разработки мероприятий по их улучшению, организовывать встречи внутри подразделений для коллективной генерации идей по улучшению, отслеживать и внедрять новейшие разработки по совершенствованию концепции внутреннего маркетинга и проводить опросы сотрудников, чтобы лучше понимать векторы развития внутреннего маркетинга организации.

\section{Библиографический список}

1. Исследование перспективности дистанционных каналов обслуживания в банковском секторе компанией McKinsey https://www.vedomosti.ru/partner/articles/2017/10/23/738959-strah-bankira

2. Документ - Стратегия развития Сбербанка $2020 / / \mathrm{https} / / /$ www.sberbank.ru/ru/about/today/strategy_2020

3. Майклз, Э. Война за таланты / Э. Майклз, Х. Хэндфилд-Джонс, Э. Экселрод; пер. с англ. Ю.Е. Корнилович.М.: Манн, Иванов и Фербер, 2005.- 272 с.

4. Rafiq M. and Ahmed P.K. The scope of internal marketing: defining the boundary between marketing and human resource management // Journal of Marketing Management. 1993.Vol. 9. No. 3. pp. 219-32.

5. Лянцевич М. Внутренний маркетинг и качество в сфере услуг. URL: https://www.cfin.ru/marketing/intmark. shtml?ck_url=1

6. Развитие маркетинга услуг и история внутреннего маркетинга // http://www.mavriz.ru/articles/2000/3/316. html

7. Новаторов Э. Международные модели маркетинга услуг // Маркетинг в России и за рубежом. 2000. № 3. C. $35-42$.

8. Шереметьева Е.Н. Методы прямого маркетинга// Вестник самарского государственного экономического университета - Самара, 2007. № 7 (33)

9. Котлер, Ф., Боуэн, Д. и Мейкенз, Д. Маркетинг: Гостеприимство и туризм. Москва. 1998

10. Развитие маркетинга услуг и история внутреннего маркетинга // http://www.mavriz.ru/articles/2000/3/316. html 